\title{
Visual and Neurodevelopmental outcomes following Abusive Head Trauma in children under 2 years of age
}

Sheethal Kodagali, Juliana Wright, Nicholas Jones, Sally Painter, Sandeep Jayawant, John Elston, Geetha Anand

\section{Aim}

To understand the immediate and long-term visual and neurodevelopmental outcomes for children following Abusive Head Trauma (AHT).

\section{Methods}

- A retrospective case series review of children aged 24 months or less, between 1995 and 2017

- A visual function score (VFS) was used to assess damage to binocular vision; score varied between 0 (normal vision) and 7 (no useful visual function)

- King's Outcome Scale for Childhood Head Injury (KOSCHI) was used to document the neurodevelopmental outcome

\section{Results}

Of the 64 cases identified, complete data obtained on 44 children ( 25 male: 19 female) with median age of 3 months
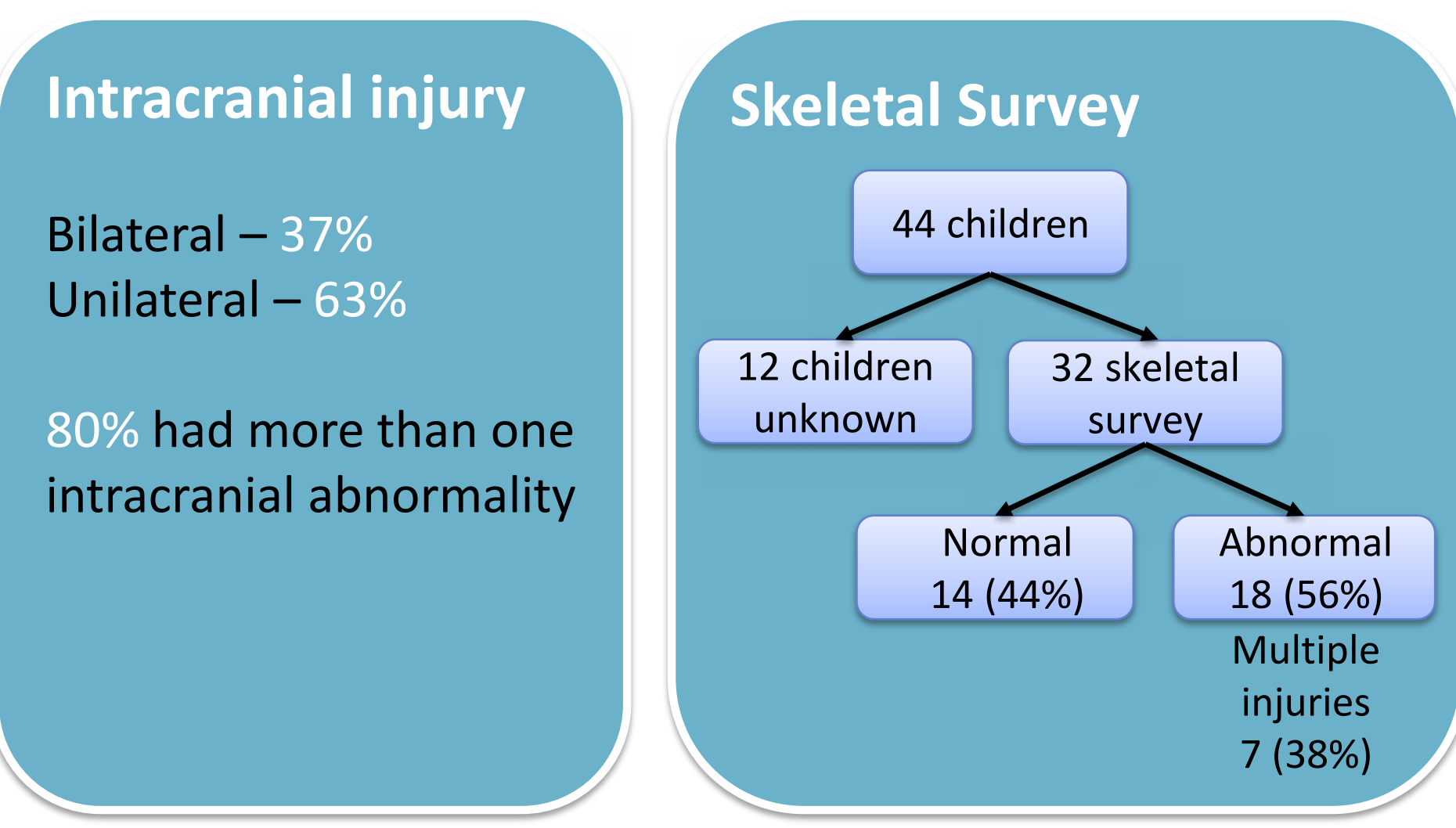

\section{Eye Findings}

- $93 \%$ had retinal haemorrhages

- Follow up range: 5 weeks - 11 years

- Mean duration of follow up: 2.6 years

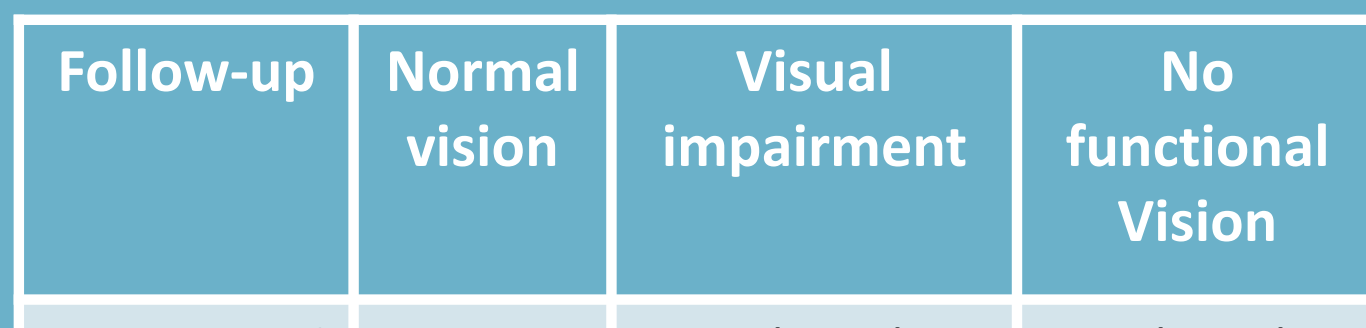

$$
\begin{array}{|l|l|l|l|}
\hline \text { Number of } & 15 & 5(22 \%) & 3(13 \%) \\
\hline
\end{array}
$$

children $(65 \%)$

Koschi Scores

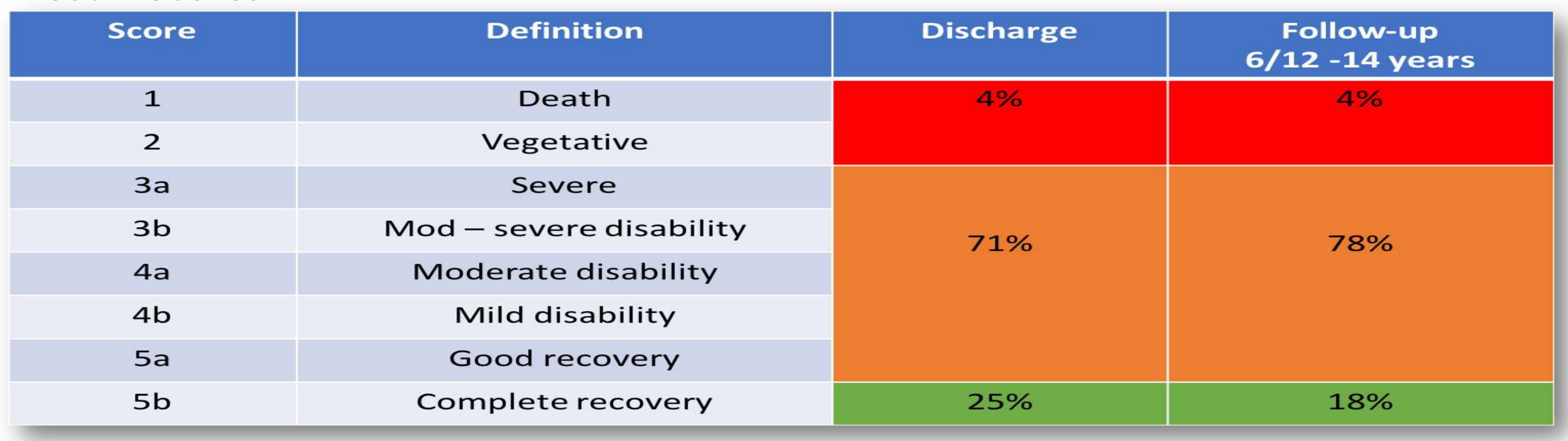

\section{Conclusion}

Significant long-term visual and neurodevelopmental disability continues to affect a large proportion of children with AHT. At long-term follow-up, further co-morbidity is identified with a proportion of our cohort showing a worsening in their $\mathrm{KOSCHI} \mathrm{score,} \mathrm{and} \mathrm{increased} \mathrm{burden} \mathrm{of} \mathrm{disability} \mathrm{into} \mathrm{middle} \mathrm{and} \mathrm{late} \mathrm{childhood.} \mathrm{Follow-up} \mathrm{should} \mathrm{reflect} \mathrm{this} \mathrm{timescale,}$ to ensure additional difficulties are accurately recognised and appropriate support made available. 